\title{
A ideologia e o significado do trabalho para trabalhadores por conta própria ${ }^{1}$
}

Fellipe Coelho-Lima. Universidade Federal do Rio Grande do Norte. Pedro F. Bendassolli. Universidade Federal do Rio Grande do Norte.

\section{Resumo}

O objetivo dessa pesquisa é analisar as características da ideologia no trabalho por conta própria a partir dos significados atribuídos ao trabalho por trabalhadores nessa situação. Realizou-se 11 entrevistas em profundidade com feirantes do Shopping de Pequenos Negócios do Alecrim, em Natal, Brasil. Obteve-se que é comum entre os entrevistados terem realizado trabalho infantil, serem oriundos de famílias de baixa renda e ter sido inserido em trabalhos precarizados. No trabalho atual, estabelecem relações contraditórias de competição e cooperação entre os demais feirantes e planejam continuar nessa atividade indefinidamente. Eles significam o trabalho como uma fonte de dinheiro e de ocupação do tempo, o trabalho assalariado como lugar de humilhação e o trabalho por conta própria como forma de realização de suas demandas. Esses significados desempenham três funções ideológicas: fixação dos trabalhadores nessa condição de trabalho, impedimento de construção de uma consciência de classe e crítica ao trabalho assalariado.

Palavra-chave: trabalho informal; ideologia; marxismo; psicologia histórico-cultural; significado.

\begin{abstract}
Ideology and meaning of work to self-employed workers. This paper aims to analyze the characteristics of the work ideology to self-employed workers, focusing on the meaning those workers ascribe to their work. Eleven in-depth interviews were carried out with people working in a Small Business Mall in Alecrim, located in Northeast Brazil. The results indicate that the interviewees started working soon in life, coming from low-income families. In the current work, they maintain competitive and cooperative relationship with each other, and they intend to keep working as marketer indefinitely. Working is signified as a source of income and as a strategy to occupy the time. Working in formal work is regarded as a source of humiliation; in the informal condition they feel they have the opportunity for self-fulfillment. The three ideological functions played by the meanings of work are: keeping the workers in their current work; hindering the emergence of a collective-class consciousness; and criticizing the salaried employees.
\end{abstract}

Keyword: informal work; ideology; marxism; historic-cultural psychology; meaning.

\section{Resumen}

La ideología y el significado del trabajo para trabajadores autónomos. Esta investigación objetivo analizar la ideología en la labor de trabajadores autónomos a partir de los significados atribuidos al trabajo por el personal en esa situación. Se llevaron a cabo 11 entrevistas con feriantes del Centro Comercial de Pequeños Negocios del Alecrim, en Natal, Brasil. Los resultados indican que es común que los entrevistados hayan realizado trabajo infantil y que procedan de familias de baja renta. En el trabajo actual, establecen relaciones de competencia y cooperación con los demás feriantes y planean continuar en esta actividad indefinidamente. Ellos significan el trabajo como una fuente de dinero y de ocupación de su tempo; el trabajo asalariado como lugar de humillación y el trabajo autónomo como forma de realización de sus demandas. Estos significados desempeñan tres funciones ideológicas: fijación de los trabajadores en esa condición de trabajo, impedimento de la construcción de una consciencia de clase y crítica al trabajo asalariado.

Palabras clave: trabajo informal; idiología; marxismo; psicología histórico-cultural; significado. 
O objetivo deste artigo, derivado de pesquisa empírica, é analisar as características da ideologia no trabalho por conta própria a partir dos significados atribuídos ao trabalho por trabalhadores nessa situação.

O trabalho por conta própria é uma das modalidades que compõe o trabalho informal, juntamente com o trabalho assalariado sem registro (Cacciamali, 2000). Ambos os fenômenos estão ligados à reestruturação produtiva e à consequente heterogenização do trabalho dela derivada (Antunes, 2016; Chen \& Vanek, 2013; Tavares, 2010). Enquadra-se no circuito de aplicação da força de trabalho, de comercialização e produção de mercadorias podendo estar organicamente ligado ao trabalho formal, respondendo à demanda atual de reprodução acelerado do capital (Cardoso, 2013; Siegmann \& Schiphorst, 2016; Tavares, 2010).

O trabalhador por conta própria se diferencia de outras formas de trabalho conceitualmente similares, na medida em que seu objetivo é a garantia de uma renda para sobrevivência - e não a reprodução de capital, como é o caso do microempresário. Atua no mercado por meio do uso intensivo de sua própria força laboral, não possuindo recursos suficientes para a aquisição de maquinário e tecnologias que garantam competitividade. Outra característica é a utilização do trabalho familiar (Cacciamali, 2000; Organização Internacional do Trabalho [OIT], 2002) e sua expansão dos países periféricos para os centrais do capitalismo (Chen \& Vanek, 2013; Siegmann \& Schiplhorst, 2016). Não será objeto de análise desse artigo, mas também há situações em que o trabalho informal é motivado por uma demanda do capital em sonegar encargos presentes na esfera formal de circulação e produção (Harvey, 2010; Tavares, 2010).

No caso específico do Brasil, aproximadamente 25,3\% dos trabalhadores estão em situação de trabalho por conta própria, recebendo, em média, $\mathrm{R} \$ 1.412,50$, o que corresponde a $65,8 \%$ do rendimento de um trabaIhador assalariado formalizado (Instituto Brasileiro de Geografia e Estatística [IBGE], 2018). Essa distância de rendimento com relação ao trabalho formal pode ser agudizada, se respeitada as diferenças de renda de acordo com o tipo de atividade realizada. Assim, de acordo com os dados disponíveis, os trabalhadores por conta própria na construção civil poderiam chegar a receber menos que a metade (44\%) do que a média de rendimentos dos trabalhadores por conta própria (IBGE, 2003).
Ainda de acordo com o mesmo estudo, a quantidade de horas trabalhadas revela uma realidade na qual $37 \%$ desses trabalhadores tinham jornadas de $40 \mathrm{~h}$ a $60 \mathrm{~h}$ semanais, com um contingente de $14,4 \%$ acima de $60 \mathrm{~h}$ semanais. Além disso, mais de $61 \%$ não possuem folga nos finais de semana, ocupando de 21 a 30 dias por mês (IBGE, 2003). Mesmo quando enfrentam algum agravamento de saúde esses trabalhadores não se ausentam de suas atividades. Registros também indicam que, na informalidade, pode-se encontrar até um acidente de trabalho por dia (Diaz, Guevara, \& Lizana, 2008; Ludermir \& Lewis, 2003).

Se, de um lado, a situação de trabalho por conta própria coloca os trabalhadores em condições de vida mais precárias quando comparados à situação de assalariado formal, por outro, há incentivos de organismos nacionais (e.g., Ministério do Trabalho e Previdência; Serviço Brasileiro de Apoio à Empresa) e internacionais (e.g., Fundo Monetário Internacional, Banco Mundial e Comissão Econômica para a América Latina e o Caribe - CEPAL) para os trabalhadores ingressarem e se manterem nessa atividade. Entre outros sinais, isso pode ser verificado na mudança do discurso dessas organizações. Na década de 1960, tal discurso se centrava no combate a esses empreendimentos, com a justificativa de que eles criavam uma concorrência desleal com as empresas formalizadas, pois não sofriam tributação fiscal. $\mathrm{Na}$ década de 1970 em adiante, porém, a ênfase muda, passando a se defender a incorporação dos trabalhos por conta própria como alternativas para enfrentar o desemprego. Contextualmente, a transformação desse discurso está associada à consolidação do desemprego estrutural pós-1970, e ao consequente crescimento do contingente de trabalhadores sem renda (Malaguti, 2001; Siegmann \& Schiphorst, 2016; Tavares, 2010).

Ao mesmo tempo em que esses discursos eram propagados em âmbito institucional, algumas investigações começaram a identificar sua reprodução pelos próprios trabalhadores. É o caso de Gómez (2011), em Bogotá, que revela posições contraditórias acerca da valorização do trabalho informal; o realizado por Busso (2009), na Argentina, que aponta a diferença de concepções a depender do tipo de trabalho por conta própria que se realiza; e o de Beloque (2015), realizado no Brasil, que apresenta a crítica produzida pelos trabaIhadores por conta própria sobre o trabalho assalariado/formal. Mais importante para os propósitos deste artigo, nossa suposição é de que tais "discursos" podem 
ser compreendidos como desempenhando o papel de uma ideologia.

Ideologia é um conceito amplamente investigado na literatura, compreendido a partir de múltiplas perspectivas (e.g., Löwy, 2010). Nesta investigação, tomamos especificamente o conceito de ideologia desenvolvido por Lukács (2013/1968). Esse autor desvia-se do debate gnosiológico acerca da ideologia (verdadeiro/falso), preferindo, em seu lugar, uma discussão ontológica, considerando a ideologia como uma das categorias do ser social. Para Lukács, a ideologia corresponde a um tipo particular de ideia desempenhando a função de regulação ou superação de um conflito social. Assim, ideologia emerge em sua obra como uma das estratégias utilizadas pelos grupos ou classes sociais para defenderem sua necessidade vital, a qual implica na negação da necessidade vital de outros grupos/ classes com os quais estejam em disputa (direta ou indiretamente). A ideologia orienta os indivíduos sobre o modo de agir diante desse conflito, podendo atuar tanto em seu mascaramento, como na instigação para sua superação (Gualdi, 2014).

Contudo, para cumprir sua função social, as ideias (na qualidade de ideologia) precisam alcançar os indivíduos em questão. Em outras palavras, precisam converter-se em prática, em ações concretas destinadas a solucionar os problemas oriundos dos conflitos sociais no cotidiano (Mészáros, 2005). Para chegar nesse nível individual a ideologia vale-se da sua materialização na linguagem, circulando em um determinado contexto social (Lukács, 2013/1968). Nossa premissa é que a ideologia alcança a sua função social por meio da linguagem pelos mecanismos de apropriação dos elementos culturais que ela possibilita, quer dizer, pela conversão da ideologia em significados socialmente compartilhados que são apropriados e metabolizados pelos sujeitos.

Para compreender a última articulação teórica proposta acima, recorremos ao trabalho de Vygotsky (2009/1934), autor para quem a linguagem dá forma às produções culturais de uma sociedade, além de, obviamente, permitir a comunicação entre as pessoas. A linguagem possui uma dimensão social de regulação das relações coletivas, e também uma dimensão individual, atuando sobre as consciências das pessoas sendo ambas interdependentes. Para Vygotsky, a linguagem é organizada em unidades dialéticas de significados (dimensão social) e sentidos (dimensão individual). A primeira faceta dessa unidade é marcada por um maior poder de generalização, permitindo que a linguagem cumpra suas funções sociais de realização da produção cultural e de comunicação. Já a segunda faceta, referente aos sentidos, possui menor poder de generalidade, estando mais próxima dos elementos particulares de cada consciência, como afetos e memórias. Para Vygotsky, são os significados "conscientizados" que permitem a ideação e a organização das práxis dos sujeitos (Vygotsky, 2009/1934).

Os debates acerca dos sentidos e significados do trabalho encontram na tradição histórico-cultural uma das abordagens possíveis para o tema. Contudo, os estudos com relação a esse tema datam já da década de 1950 (e.g., Morses \& Weiss, 1955), alcançando maior repercussão a partir dos anos 1980 , com o advento da pesquisa transcultural Meaning of Work (MOW, 1987). No Brasil, se configura atualmente como um dos cinco temas mais estudados no campo da Psicologia do Trabalho e das Organizações, havendo pluralidade teórico-metodológica nessas investigações (e.g., Schweitzer, Gonçalves, Tolfo, \& Silva, 2016). As pesquisas sobre sentido e significado, de maneira geral, têm evidenciado a diversidade de atribuições conferidas ao trabaIho, todavia, havendo maior ênfase no seu aspecto instrumental (Harpaz \& Meschoulam, 2004; Peixoto \& Borges, 2015; Person, May, \& Mayer, 2016). Igualmente, tem atentado para a centralidade que o trabalho possui na vida das pessoas, comparando-o a outras esferas de vida, sofrendo impactos da cultura de cada país e dos papéis de gênero, sendo comum ter menos importância, apenas, do que a família (e.g., Lu, Huang, \& Bond, 2016). Outras linhas de pesquisa tem se dedicado a identificar que condições objetivas e subjetivas são necessárias para que o trabalho possa ter sentido para as pessoas (e.g., Morin, 1997; 2002). Além de evidenciar o seu papel na dinâmica de determinação da saúde, bem-estar e qualidade de vida no trabalho e diversos comportamentos organizacionais (e.g., Rosso, Dekas, \& Wrzesniewski, 2010).

Nosso pressuposto é de que, se os significados sociais incorporados na consciência orientam (ou ajudam) a organização da práxis das pessoas, o mesmo pode acontecer com a ideologia. Ao oferecer uma orientação social, na forma de discursos ou narrativas sociais, genéricas, produzidas e divulgadas por grupos ou classes sociais interessadas na manutenção ou solução de determinadas contradições sociais, a ideologia alcança as consciências na forma de significados internalizados, via linguagem. É na sua prática sobre o cotidiano que aqueles significados sociais (ou 
ideologias) são incorporados, pela via do processo de produção dos sentidos, aos afetos e às estruturas cognitivas das pessoas, e estas à sua ação. Portanto, há um espaço entre a ideologia produzida pelos grupos ou classes sociais e o modo como ela se relaciona à práxis cotidiana, não havendo uma simples sobreposição ou internalização unilateral desse conteúdo.

A partir dessas considerações espera-se contribuir, com os achados dessa pesquisa, para a construção de uma visão crítica sobre a função social dos sentidos e significados presentes no cotidiano dos trabalhadores informais, trazendo ainda informações sobre a manutenção dos trabalhadores nessa forma de trabalho.

\section{Método}

\section{Participantes}

O universo deste estudo compreende o conjunto de trabalhadores por conta própria atuando no setor de circulação de mercadorias como feirantes de produtos industrializados com ponto fixo. Portanto, trata-se aqui, da informalidade de rua, mais especificamente, de camelôs: aqueles que, diferentemente dos ambulantes, possuem um espaço físico definido e, em alguma medida, garantido ao longo do tempo para realizar a sua atividade (Durães, 2013). Com base na caracterização feita na literatura (e.g., Cacciamali, 2000; Durães, 2013; OIT, 2002; Tavares, 2010), definiu-se como critérios de inclusão: ser um trabalhador por conta própria com local fixo e dono do próprio negócio ("barraca"); possuir, no máximo, dois outros trabalhadores como auxiliares; ter como foco a obtenção de renda para sobrevivência; participar integralmente do processo de trabalho; e não possuir ensino superior completo.

Considerando o histórico de concentração desse tipo de trabalho e critérios de conveniência, abordou-se os trabalhadores por conta própria que desenvolviam suas atividades no Shopping de Pequenos Negócios do Alecrim - ou Camelódromo do Alecrim em Natal, capital do Rio Grande do Norte. Para a delimitação do número de participantes, nos valemos de procedimento de saturação teórica (e.g., Fontanella et al., 2011).

No presente caso, a referida saturação foi alcançada com 11 participantes, distribuídos entre os dois gêneros de modo quase idêntico. Ademais, destacam-se as seguintes características: formação escolar entre o ensino fundamental incompleto até o ensino técnico; idades variando entre 25 e 48 anos; tempo mínimo de dois anos e máximo de 30 anos de presença no
Camelódromo; atuação nos setores de vestuários (seis casos), acessórios e manutenção de celular (dois casos), calçados, venda de CDs e DVDs "piratas" e livros usados (cada um com um caso). Esse conjunto de características é semelhante às encontradas em outros estudos no Brasil (e.g. Machado \& Rocha, 2003; Rebouças, 2011), e em outros países da América Latina (e.g. Busso, 2009).

\section{Instrumento e Procedimentos}

A coleta dos dados foi realizada entre os meses de outubro e dezembro de 2015. Foram conduzidas entrevistas em profundidade (Johnson, 2002), com os participantes em seu próprio local de trabalho. Inicialmente, realizou-se uma aproximação com o campo, a partir de algumas entrevistas assistemáticas, a fim de apreender a dinâmica de funcionamento daquele espaço. A partir delas foi possível adequar o roteiro de pesquisa ao público; optar por utilizar uma identificação visual, a fim de assegurar aos participantes que não se tratava de uma fiscalização; e apreender as condições gerais em que seria possível realizar as entrevistas.

Para a coleta de dados propriamente dita, o pesquisador estabeleceu como rotina a realização de visitas semanais ao local, em uma média de três vezes por semana. Foi também durante tais visitas que as entrevistas foram realizadas. A abordagem com os feirantes ocorreu de forma direta, convidando-os para participar da pesquisa. Foram abordados 40 proprietários de barracas e 11 aceitaram participar da entrevista - os que não aceitaram o fizeram sem justificativa. A exigência que os participantes fizeram para colaborar com o pesquisador era de que seriam proibidas gravações, por receio que se tratasse de uma fiscalização. Portanto, a fim de viabilizar a realização dessa investigação, optou-se pela via do registro indireto das informações. As entrevistas duraram, em média, 1 hora e 30 minutos.

No registro indireto, o pesquisador, valeu-se de 1) registros escritos (diários de campo) feitos durante a realização da entrevista, 2) e da elaboração, para cada participante, de um texto no qual foram condensadas as principais ideias discutidas durante a conversa. Tais ideais foram registradas em termos de seu significado geral, sendo registrada no diário de campo, durante a entrevista, algumas frases e palavras literais mais representativas de determinadas respostas. Para cada participante, e de forma homogênea, eram sintetizados os principais elementos abordados para cada item daquele roteiro. Para minimizar a perda de detalhes do conteúdo 
das entrevistas, seguiu-se as sugestões de Edwards e Holland (2013), em se realizar um registro completo imediatamente posterior à entrevista. Para tanto o pesquisador dirigia-se a um local isolado, próximo ao Camelódromo, e gravava o seu próprio relato sistemático sobre cada item da entrevista, com o auxílio das anotações do diário de campo e do roteiro utilizado para a entrevista. Esse material foi posteriormente transcrito, de modo que o corpus da análise consiste precisamente das transcrições daquelas gravações.

A fim de garantir a confiabilidade dos dados oriundos da pesquisa, os relatos produzidos, após serem transcritos, foram apresentados a cada participante, podendo ele acrescentar, retificar ou corrigir o que julgasse necessário. Esse procedimento recebe nomes diversos na literatura - member checking (Braun \& Clarke, 2013), communicative validation (Flick, 2006), member validation (Seale, 1999) ou recall (Edwards \& Holland, 2013) - e tem por objetivo garantir a credibilidade, veracidade e validade das informações que fundamentam as análises em estudos qualitativos.

É preciso considerar que a análise realizada não se baseou em palavras singulares empregadas pelas pessoas, mas na sua significação em contexto. Assumimos que, contanto que as principais unidades de significação (respostas a cada tópico do roteiro) fossem preservadas, a qualidade do material seria assegurada, permitindo a continuidade do processo de análise. As frases e palavras literais registradas figuraram muito mais como uma síntese pessoal do participante ou como um exemplo do significado comunicado, do que como a base principal da análise. Dessa forma, o próprio resgate desses elementos na seção de Resultado tem o objetivo de exemplificar os significados apreendidos. O roteiro que serviu de base para a condução das entrevistas foi composto por quatro eixos específicos, conforme apresentado na Tabela 1.

Tabela 1. Composição do Roteiro de Entrevista

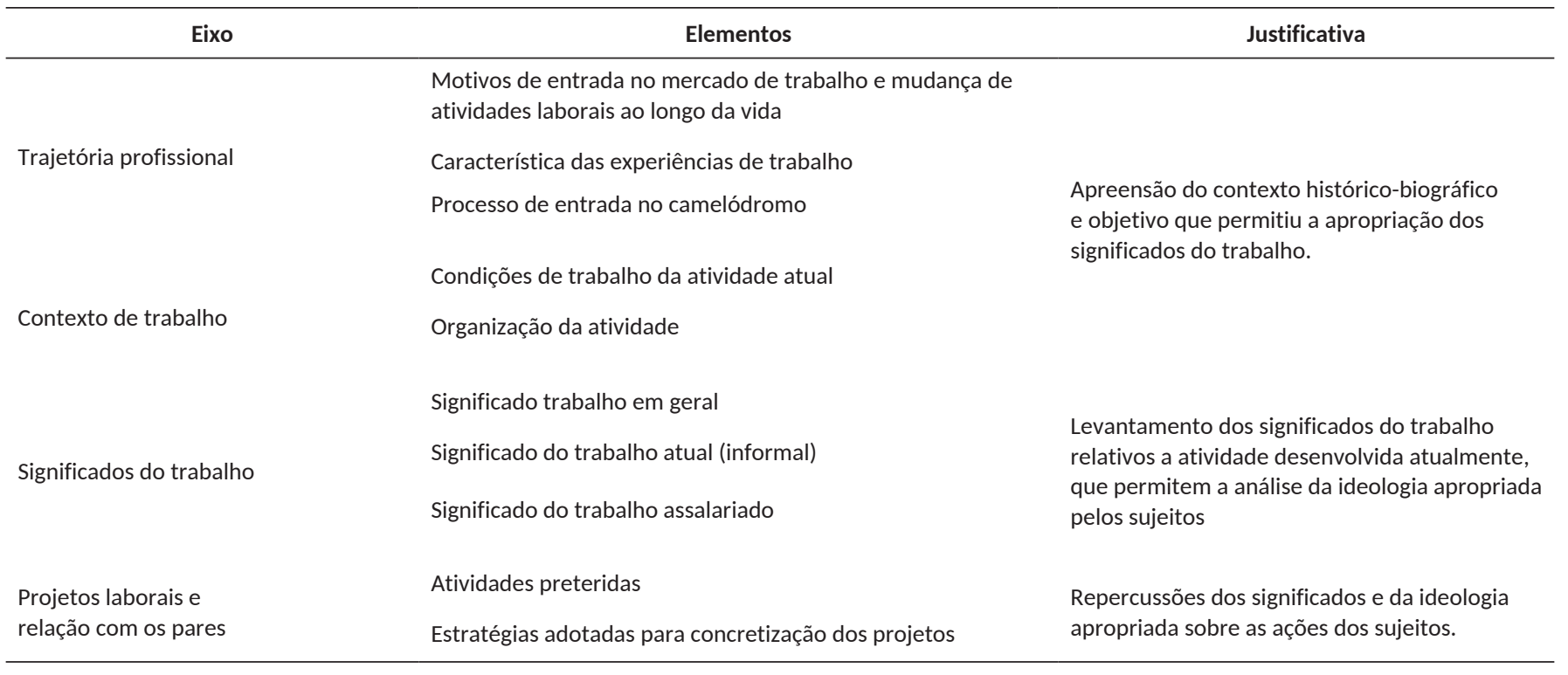

\section{Processo de Análise dos Dados}

O corpus da análise consistiu do texto produzido a partir da transcrição do relato para cada participante, feito pelo pesquisador. Esse material textual possuiu o tamanho médio de dez laudas por participante e utilizou-se como suporte para organização e análise do material o programa QDA Miner 5.0 da Provalis Research.
Essencialmente, o material foi organizado com base em procedimentos usuais de categorização qualitativa (e.g., Bauer, 2000). Primeiramente, em uma análise intra-caso, o foco era identificar trechos que se referissem às temáticas abordadas na pesquisa e que são materializadas no roteiro de entrevista (que funcionou como balizadores ou grande categorias $a$ priori) (Tabela 1). O resultado desse procedimento foi 
registrado em ficha para cada participante, no formato de códigos (Bauer, 2000). Em seguida, o nível da análise mudou para os casos em sua comparação mútua (inter-casos). O foco era identificar pontos de semelhança entre os relatos (análise inter-casos), mantendo o foco nos quatro balizadores que guiaram o roteiro de entrevista.

Essas duas estratégias de análise, codificação intra-caso e comparação inter-casos, foram complementadas por um processo de categorização final, quando então, a partir dos pontos de convergência, foram sendo elaboradas as categorias centrais de análise e que organizam todo o material num processo de generalização indutiva do conteúdo das entrevistas para categorias teóricas. Por fim, estas últimas foram submetidas a uma dupla análise teórica. Na primeira, buscou-se apreender os significados comunicados pelos participantes; na segunda, buscou-se identificar, na unidade de sentidos-significados, elementos componentes da ideologia em operação, na acepção dada a este termo na introdução deste artigo.

\section{Resultados}

As quatro grandes categorias teóricas, cujo processo de elaboração foi descrito na etapa anterior, são as seguintes: a) trajetória de vida laboral, b) organização do trabalho atual, c) significado do trabalho e d) relação com os pares e projeto laboral. Nesta seção, seguimos essa ordem para descrever os resultados encontrados. Os nomes apresentados para cada participante são fictícios.

\section{Trajetória de Vida Laboral}

Esta categoria reúne os elementos relativos à vida laboral pregressa dos participantes, buscando reconstruir os vários momentos dessa trajetória até sua situação atual, atuando no Camelódromo (ver Tabela 1). Quando apreciados em conjunto, como grupo (análise intergrupal), é possível identificar quatro marcadores comuns relativos à trajetória laboral dos participantes: a) serem oriundos de famílias de baixa renda; b) terem trabalhado desde criança; c) possuírem uma ampla diversidade de experiências em diferentes trabaIhos; e d) terem como foco a busca por melhor renda na mudança de atividades laborais.

Quanto à origem dos participantes, é marcante terem um contexto, na infância, marcado por dificuldade financeira para assegurar a sobrevivência da família. Também apareceu como característico desse contexto famílias numerosas, com todos os membros trabalhando. Para os entrevistados, foi a partir dessa situação de pobreza que se identificou a necessidade do trabalho desde a infância ou, mais tardar, na adolescência - começaram a realizar atividades remuneradas entre 6 e 15 anos de idade. Paulo, um dos participantes, exemplifica esse contexto familiar de origem. Provém de uma família com diversos irmãos e com dependência exclusiva da renda do seu pai, o qual, ainda durante a sua infância, os abandonou. Como resultado, ele começou, aos 12 anos a vender a comida que a sua mãe preparava nas ruas da sua cidade natal.

As atividades desempenhadas nesse primeiro momento da vida incluíam: cuidados de outros parentes; emprego como diarista ou doméstica; trabalho em feiras; venda ambulante; e realização de diversos serviços pequenos, ou "bicos". Houve situações em que esse trabalho infantil ocorreu dentro de indústrias, evidenciando o uso de trabalho informal e ilegal por unidades produtivas formalizadas.

Seja por iniciativa própria ou, mais comum, por algum tipo de pressão ou necessidade, tão logo os participantes começaram a trabalhar nunca mais pararam. Outro aspecto comum é o engajamento dos participantes em tipos diferentes de atividades (ao menos quatro trabalhos diferentes ao longo da vida). Identificou-se, nas trajetórias, trabalho autônomo, familiar, assalariado com e sem carteira, comissionado e "bicos". Para eles, o trabalho informal atual não é novidade no rol de suas experiências, bem como o trabalho por conta própria.

Contudo, o primeiro contato especificamente com o trabalho como feirante ou camelô ocorreu em períodos distintos de vida - podendo tanto ter sido na infância, como na vida adulta. Por exemplo, Fabiano, um dos participantes, começou a trabalhar em feiras livres com 15 anos, auxiliando seu pai na venda de sapatos no interior da Paraíba; enquanto que Das Dores apenas teve contato com o trabalho enquanto camelô ${ }^{\text {com }} 30$ anos de idade.

Entre as principais razões para estar na atividade atual destacam-se motivos similares aos já apresentados anteriormente em relação à trajetória pregressa (ajudar na renda familiar), mas também casos em que o participante ativamente decidiu por abrir um negócio no local, bem como os que iniciaram como auxiliares, antes de ter sua própria barraca. Evidência desse histórico no trabalho informal como camelô é os participantes não estarem, durante o período da entrevista, pela primeira vez nessa forma de trabalho. Constava como 
motivação para terem procurado essa forma de trabaIho, a expectativa de conseguir uma melhor condição de vida, algo que julgavam não conseguir obter no trabalho formal (ou do qual foram excluídos). Busca por "liberdade" e "autonomia" também apareceram nos relatos. Essas características são expressas exemplarmente no relato de Margarida, ao indicar que ela mesma que solicitou sua demissão do cargo de vendedora em uma empresa para montar uma barraca de venda de roupa na frente da sua própria casa, antes mesmo da inauguração do Camelódromo do Alecrim.

\section{Organização do Trabalho}

Conforme indicado na Tabela 1, foram abordadas quatro dimensões do modo de organização do trabalho. A primeira diz respeito à jornada. É hegemônica a declaração de que há uma flexibilidade nos horários de trabaIho, sendo o próprio feirante responsável por determinar o turno de abertura e fechamento de sua banca. Porém, quando questionados sobre exatamente qual horário seria esse, todos reportam um período fixo e mais ou menos semelhante entre as bancas. Para definição do horário de funcionamento, eles relataram usar dois critérios: demandas da vida particular e, sobretudo, fluxo de clientes. Vitória materializa essa situação ao narrar que tem como horário de trabalho das $7 \mathrm{~h}$ às $17 \mathrm{~h}$, tendo escolhido esse período em função do fluxo de clientes: a própria alteração do horário de abertura das $7 \mathrm{~h}$ para as $6 \mathrm{~h}$ que ocorre em dezembro, é motivado pelo maior quantidade de compradores que o período natalino provoca.

O fluxo de clientes no Camelódromo também é determinante para a decisão sobre "folgas". Todos disseram que podem folgar no momento em que desejarem; ao mesmo tempo, porém, não conseguiam se lembrar da última vez que o fizeram fora dos finais de semanas e feriados. Isso inclui afastamentos por questões de saúde - da mesma forma, não sabiam citar a última vez em que se ausentaram do trabalho devido a esse motivo. Para eles, folgas significa deixar de auferir rendimentos e na possibilidade de perder clientes. Como expressa Madalena: "quando a gente fica gripada, é lá mesmo [no Camelódromo] que cura".

\section{Significado do Trabalho}

Nesse ponto específico, o conteúdo das entrevistas tratou de aspectos relativos às significações associadas ao trabalho (ver Tabela 1). Em geral, nota-se uma valorização positiva do trabalho entre os participantes. Dois grandes significados emergiram das entrevistas, descrevendo o trabalho como sobrevivência e como ocupação do tempo.

A primeira acepção foi a resposta imediata de todos os participantes, sendo traduzido em falas como "[Trabalho é o] que faz a pessoa crescer [materialmente]" (Vitória); "ter sobrevivência, é poder criar os filhos, criar mulher, criar família, ter dinheiro para família" (Honório); "As pessoas trabalham porque precisam" (Madalena); e "Trabalho por necessidade, para ter dinheiro" (Paulo). Notadamente, o trabalho é concebido como um mediador para o acesso a bens e serviços. Quando solicitados a complementar essa afirmação, muitos deles associaram o trabalho a consumo, como uma forma de satisfazer as necessidades materiais, conforme relatado por Fabiano: "é muito bom trabaIhar; não tem coisa melhor do que ter um passeio, viajar... E é pelo trabalho que se tem esse dinheiro".

Outro significado atribuído ao trabalho é relativo à ocupação do tempo. Exceto por uma única participante, que tinha a intenção de se aposentar, todos os demais mencionaram que continuariam trabalhando, mesmo se não dependessem da renda dali derivada. O trabalho foi significado como uma atividade permitindo o investimento do tempo, mas também a própria autovalorização, bem como o desenvolvimento de laços sociais e a manutenção da saúde, como disse Silvestre: "se o cara parar a doença chega logo".

Considerando que todos os participantes já tiveram alguma inserção no trabalho assalariado formal, questionamos qual o significado dessa forma de trabaIho para eles. Os participantes destacaram significados negativos, a saber: baixa remuneração; cobranças de gestores; exploração; falta de liberdade; e humilhação. Quer dizer, o trabalho assalariado foi apresentado como fonte de exploração, palco de assédio moral por parte de gestores, altas exigências, baixa remunerações. Cesária sintetizou o tópico afirmando que até quando ela saía de folga ou de férias o sentimento era de "uma presa saindo da prisão" e que tudo ao redor era "novo". O único aspecto positivo destacado pelos participantes quanto ao trabalho assalariado é o acesso aos direitos trabalhistas, como férias remuneradas, $13^{\circ}$ salário, licença maternidade e aposentadoria. Margarida exemplifica isso, ao relatar que foi uma "burrada" ter saído do antigo emprego e perder o acesso a esses direitos.

Em relação ao significado do trabalho atual, como feirante, as designações foram positivas. O principal ponto positivo destacado foi o nível de remuneração 
obtido, comparativamente elevado, e graças ao qual a maioria dos participantes conseguiu construir suas vidas. Exemplo disso é Fabiano que relata ter conseguido pagar a faculdade das duas filhas com o dinheiro auferido no Camelódromo. Outro aspecto positivo destacado foi "trabalhar para si mesmo". Esse significado implica em ser seu próprio "patrão" ou "patroa" (como relata Vitória e Madalena), com maior autonomia. Esse quadro majoritariamente positivo atribuídos ao trabalho informal apontam para um cenário no qual essa atividade revela-se a própria antítese ao trabalho assalariado.

\section{Relação com os Pares e Projeto Laboral}

Esta categoria congrega tópicos abarcando a relação com pares e projetos futuros. Em geral, o relacionamento com os outros feirantes é marcado pelo binômio cooperação-competição. Quanto ao primeiro polo, o que se observa no Camelódromo é que há o desenvolvimento, de maneira generalizada, de relações amistosas entre os feirantes, principalmente entre os que estão fisicamente mais próximos. Agrega-se a essas relações algumas ajudas esporádicas, como a indicação de clientes para outros feirantes; ou o repasse de produtos para outros feirantes venderem. Todos os dois casos foram constatados durante a entrevista: no primeiro, após consulta de dois clientes a Cesária se ela possuía determinado tipo de peça de roupa, a mesma indicou eles dirigirem-se a outra barraca específica para verificar; e no segundo, Fabiano foi interpelado por um colega de barraca se o mesmo poderiam vender um modelo específico de tênis que apenas Fabiano possuía, tendo resposta positiva. Por seu turno, as relações de competição entre os feirantes são observadas em torno de estratégias para "roubar o cliente um do outro", como relatou Vitória.

Ainda abordamos o modo como os feirantes organizam-se para resolver problemas coletivos. A forma privilegiada escolhida por eles é o recurso à Associação de Feirantes. Contudo, eles destacaram que essa atuação é limitada, tanto por dificuldades financeiras, resultado da inadimplência no pagamento das cotas mensais, como pela falta de envolvimento dos feirantes.

Com relação aos planos para o futuro, eles são os mais variados possíveis: retornar ao trabalho assalariado, mantendo o box no Camelódromo; realizar melhorias no ambiente de trabalho atual; abertura de lojas formalizadas para comercialização dos mesmos produtos que trabalham atualmente; ingressar em uma carreira profissional, a depender de concluir curso superior; reduzir a carga horária de trabalho no Camelódromo; aposentar-se; e continuar no trabalho atual sem alterações. Dois aspectos são comuns a essa miríade de planos: a dificuldade em projetar o futuro no trabalho; e o desejo da maioria de continuar trabaIhando, sem intenção alguma de interromper essa atividade. Essa posição é independentemente da idade, tempo de trabalho ou da possibilidade de acesso à aposentadoria. Honório representa essa situação, pois, ao mesmo tempo, hesitou três vezes em responder a essa questão e, ao fazer, apenas relatou querer continuar no box por tempo indeterminado.

\section{Discussão}

Esta pesquisa identificou que, no âmbito dos significados gerais ou compartilhados, o trabalho informal é entendido pelos participantes como fonte de renda e como atividade capaz de ocupar o tempo. Já o trabalho formal, assalariado, foi caracterizado principalmente como algo negativo. Ponderando as ênfases, notamos que os participantes tenderam a ter uma visão hipervalorizada de seu trabalho na informalidade. Quais poderiam ser as explicações para a emergência desses significados?

A valorização prioritária dos aspectos econômicos e instrumentais do trabalho não é novidade na literatura sobre significado do trabalho, principalmente quando se trata dos trabalhadores pauperizados (e.g., Harpaz \& Meshoulam, 2004; Peixoto \& Borges, 2015). Esse é o caso dos participantes desta pesquisa: possuem um histórico de vida e familiar marcado pela ausência de recursos suficientes para a manutenção básica, sendo a sobrevivência material algo imanente em seu sistema de valores. Se, para os participantes, o trabalho que realizam aparece na forma de sobrevivência, para o conjunto das relações sociais capitalistas é condição de reprodução do próprio capital (Antunes, 2016).

Também é notória a centralidade que o trabalho assume em comparação com outras esferas de vida. Pelos relatos obtidos, o trabalho é um dos motores organizadores da vida dos sujeitos, estando atrelado, não só a sua própria sobrevivência, como a da sua família. Essa conformação é semelhante a encontrada em outros estudos de caráter transcultural (e.g., Lu et al., 2016).

Ademais, a heterogeneização do mundo do trabaIho intercala a existência concomitante de um pequeno conjunto de trabalhos assalariados, em geral com 
melhores condições, e de um grupo dos trabalhadores hiperprecarizados, sem acesso a direitos trabalhistas e remuneração apropriada. Este último grupo é composto pelos trabalhadores por conta própria, subcontratados, contratados por agências, entre outros (Harvey, 2010). E é exatamente nesta última camada que estão situados os participantes desta pesquisa, o que também explica suas trajetórias laborais marcadas por intensa rotatividade entre empregos, alternando trabalho formal e informal. Para eles, no plano psicológico, a motivação era por "melhorar de vida" ao trocar de empregos. Porém, no plano objetivo das relações de trabalho essa motivação contribui para a manutenção da própria lógica da precarização a que estão submetidos.

O resgate da classe social de origem dos participantes permite apreender uma das possíveis razões pelas quais o trabalho assalariado é significado como um espaço de humilhação. Isso ocorre porque sua própria condição os dispõe a ambientes mais violentos de trabalho, sem qualquer atenuação desse tipo de prática. Isso é agravado pela própria dinâmica do capitalismo em países periféricos, como é o caso do Brasil (Antunes, 2016), onde se concentram altos níveis de trabalhos precários, além dos reflexos de um escravismo apenas tardiamente abolido (Mattos, 2009).

Associa-se a esse significado do trabalho assalariado a busca pelo trabalho "sem patrão". Diante da repulsa às diversas formas de humilhação promovidas nos espaços laborais empresariais, boa parte dos participantes da pesquisa elaboram o desejo por "trabalhar para si mesmo". Na prática, esse interesse encontra reforço em diversos discursos socialmente divulgados, ao menos desde a década de 1990, referente ao microempreendedorismo, associando ao trabalho por conta própria uma saída legítima e valorizada para o desemprego e a precarização. Porém, como já demonstrado (e.g., Castro \& Nunes, 2014; Malagutti, 2001), a saída do pauperismo pela via do empreendedorismo constitui-se em uma falácia, pois nele permanece a submissão do trabalhador a condições aviltantes de trabalho.

É importante ressaltar que enquanto outras pesquisas têm apontado as características necessárias de um emprego para ter sentido (e.g., Morin 1997; 2002; Rosso et al., 2010), o que a presente investigação pode apontar é uma possível falência, por parte dos participantes, em buscar esse sentido nos empregos formais, tendo-o encontrado no trabalho como camelô.
Nesse contexto, e retomando os objetivos desta pesquisa, qual seria a função ideológica desses elementos identificados nos significados atribuídos ao trabaIho informal? Três funções sociais específicas podem ser neles identificadas: a primeira é a conformação de parcela da classe trabalhadora à forma de trabalho por conta própria; a segunda é o combate à construção da solidariedade e consciência de classes entre esses trabaIhadores; e a última é a crítica ao trabalho assalariado.

A primeira função pode ser observada no desejo desses trabalhadores em permanecer na atual forma de trabalho. É significativo que o interesse de permanência se mostre na supervalorização dessa forma de trabalho, mesmo diante das diversas insalubridades no contexto do camelódromo. Porém, a permanência nesse tipo de trabalho tem como efeito a autorresponsabilização dos trabalhadores pela sua condição de vida atual. Se essa é uma tendência tradicionalmente analisada dentro das empresas (Antunes, 2016), ela também está presente no trabalho por conta própria.

Como pudemos observar a partir das entrevistas, o significado de "trabalhar para si" refere-se à percepção de que todo o processo produtivo está sobre o controle do trabalhador. Embora isso seja factível, ao menos quando comparamos essa situação àquela de muitos trabalhadores em organizações formais, essa percepção pode ser distorcida. O modo como os participantes se comportam em relação à organização de seus horários e folgas ilustra tal distorção, pois ao mesmo tempo em que afirmam ter possibilidade de escolha para determinar sua jornada de trabalho, essa escolha é objetivamente condicionada pelo fluxo de consumidores que frequentam o camelódromo. Logo, o que realmente se opera não é uma completa liberdade de escolha, por parte do trabalhador, de todos os seus processos e determinações do trabalho, mas sim a internalização desse controle externo, algo semelhante ao que ocorre nas fábricas toyotizadas (Alves, 2011).

A significação do trabalho por conta própria como um trabalho no qual o trabalhador organiza o seu processo de trabalho livremente pode estar servindo a uma mistificação das relações de produção a qual esses trabalhadores estão submetidos: se, em sua perspectiva pessoal, o seu trabalho tem seu início e fim no próprio espaço do Camelódromo, o mesmo é apenas um elemento dentro de uma cadeia produtiva mais ampla, que engloba diversos outros trabalhadores das indústrias, dos transportes e no próprio consumo dos bens. Desse modo, o trabalhador acaba por não se dar conta 
dos reais determinantes do seu trabalho, recaindo na individualização e na autoresponsabilização dos problemas que enfrenta, esvaziando, dessa forma, o conteúdo social dos mesmos, convertendo-os em questões exclusivamente pessoais.

Uma segunda função social cumprida pelos significados do trabalho encontrados entre os camelôs é o de, paradoxalmente, afastar os próprios trabalhadores. Como já exposto, um comportamento comum no camelódromo é a competição entre os próprios trabaIhadores, decorrente, em grande parte, de um ambiente de vendas (luta por clientes). Parte dessa competição pode ser motivada pelo significado do trabalho como fonte de dinheiro, associada à busca pela satisfação de necessidades individuais pela própria sobrevivência, mesmo quando os demais trabalhadores do camelódromo possuem a mesma necessidade.

Na pressão interna pela sobrevivência e pela maximização dos ganhos financeiros, os participantes mal podem perceber o abandono do próprio espaço público que possibilita a realização de seu trabalho (entre eles, o desinvestimento da Associação). Mesmo que o fomento à competição entre os trabalhadores também seja motivado por um significado do trabalho atrelado ao dinheiro, não se pode perder de vista que esse comportamento sofre direta influência do ideário individualista mais amplo, no qual as lutas coletivas por meio da organização da classe são desvalorizadas (Harvey, 2010).

A terceira função da ideologia do trabalho aqui identificada está associada à crítica ao trabalho assalariado. De modo interessante, isso sugere um processo inverso ao descrito por Anthony (2014), pelo qual, na emergência do capitalismo, foi fundamental a elevação moral e ideológica do trabalho assalariado como forma de garantir a adesão dos trabalhadores às novas condições de trabalho fabril. O que esconderia essa crítica ao trabalho assalariado? Uma negação dessa ideologia da glorificação do trabalho? Parte do poder dessa crítica é, contudo, absorvido pelo próprio capitalismo na forma de valorização ao microempreendedorismo (Castro \& Nunes, 2014; Malaguti, 2001), como constatado nesta pesquisa em torno da valorização do significado de ser "seu próprio patrão".

Ao mesmo tempo em que os trabalhos informais representam um aspecto da precariedade do trabalho na atualidade, a sua distância do centro da reprodução capitalista (que corresponde ao trabalho formal), representa também o distanciamento das relações sociais estereotipadas existentes nesse meio, permitindo a construção de outros padrões de relações sociais (Cardoso, 2013). Em alguma medida, esse posicionamento dentro do mundo do trabalho (periférico, precário e no limiar da funcionalidade à reprodução do capital) permite que outras facetas do trabalho, que não apenas a extração de mais valor e todas as suas consequências, sejam, ainda que timidamente, reveladas.

Assim, o que podemos afirmar, diante dessas três funções identificadas, é que existe uma ideologia específica fomentada para o trabalho por conta própria. Ela tem como seus pilares, do ponto de vista das consciências particulares, os significados do trabaIho atrelados à sua equivalência à obtenção de dinheiro e sobrevivência, supervalorização do trabalho por conta própria - motivado pela (suposta) liberdade de organização do trabalho e pela obtenção de renda superior ao trabalho formal - e a desvalorização do trabalho formal. Enquanto ideologia, o conflito ao qual tentam oferecer orientações corresponde à utilização da força de trabaIho na atual etapa do capitalismo. A forma de enfrentar a contradição em tela que esse conjunto de ideias indicam é de negação do trabalho assalariado, mas de manutenção da produção e do trabalho nos marcos capitalistas de reprodução e submissão ao capital. Isso ocorre no instante em que se mantém em formas de trabalho precarizadas, sem o fomento prioritário de laços de solidariedade com os demais trabalhadores nessa situação, bem como garantindo a existência desse espaço de comercialização fundamental a circulação de tipos específicos de mercadoria dentro do capitalismo.

Ao finalizar esse artigo, cabem duas considerações. A primeira é a possibilidade de uso dos significados como meio de analisar a ideologia presente no cotidiano, quando se incorpora às análises subjetivas e biográficas, às condições sociais e finalidades sociais desses significados. A segunda é que, se por uma via foi apresentado o lado nefasto da força ideológica, por outro, também é apontado o potencial de resistência da vida humana em seu processo de construção de sentido e transformação das condições reais de existência por meio da práxis.

\section{Referências}

Alves, G. (2011). Trabalho e Subjetividade. São Paulo: Editora Boitempo. Anthony, P. D. (2014). The ideology of work. Londres: Routledge.

Antunes, R. (2016). The new morphology of labour and its main trends: Informalisation, pracarisation, (im)materiality and value. Journal of Socialist Theory.44(1-2), 13-30. doi: 10.1080/03017605.2016.1173822 
Bauer, M. W. (2000). Classical content analysis: A review. In M. W. Bauer \& G. Gaskell (Orgs.), Qualitative researching with text, image and sound: a practical handbook for social research (pp. 131-151). Londres: Sage.

Beloque, L. D. (2015). A cor do trabalho informal: uma perspectiva de análise. São Paulo: Novas Edições Acadêmicas.

Braun, V., \& Clarke, V. (2013). Successful qualitative research. Londres: Sage.

Busso, M. (2009). Cuando el trabajo informal es espacio para la construcción de identificaciones colectivas: un estudio sobre ferias Trabajo, empleo, comerciales urbanas. In J. C. Neffa, E. G. Toledo, \& L. M. Terra (Orgs.), Calificaciones profesionales, relaciones de trabajo e identidades laborales (pp. 159-192). Buenos Aires: CLACSO.

Cacciamali, M. C. (2000). Globalização e processo de informalidade. Economia e Sociedade, 9(1), 153-174. Recuperado de https:// periodicos.sbu.unicamp.br/ojs/index.php/ecos/article/view/8643124

Cardoso, A. (2013). Ensaios de sociologia do mercado de trabalho brasileiro. Rio de Janeiro: FGV.

Castro, C. A., \& Nunes, T. G. (2014). Crítica à razão empreendedora: sobre a função ideológica do empreendedorismo no capitalismo contemporâneo. Revista de Derechos Humanos y Estudios Sociales, 6(11), 117-135. Recuperado de http://www.derecho. uaslp.mx/Documents/Revista\%20REDHES/N\%C3\%BAmero\%2011/ Redhes11-06.pdf

Chen, M. A., \& Vanek, J. (2013). Informal employment revisited:Theories, data and policies. Indian Journal of Industrial Relations, 48 ${ }^{(3)}$ ), 390-401. Recuperado de https://www.jstor.org/stable/23510786

Diaz, E. M., Guevara, R. C., \& Lizana, J. L. (2008). Informal work: Motives, well being, health and happiness in street vendors. Psicologia em Estudo, 13(4), 693-701. doi: 10.1590/S1413-73722008000400007

Durães, B. (2013). Camelôs globais ou de tecnologia: novos proletários da acumulação. Salvador: EDUFBA.

Edwards, R., \& Holland, J. (2013). Whats is Qualitative Interviewing? Londres: Bloomsbury.

Flick, U. (2006). An introduction to qualitative research Londres: Sage.

Fontanella, B. J. B., Luchesi, B. M., Saidel, M. G. B., Ricas, J., Turato, E. R., \& Melo, D. G. (2011). Sampling in qualitative research: a proposal for procedures to detect theoretical saturation. Reports in Public Health, 27(2), 388-394. doi: 10.1590/S0102-311X2011000200020

Gómez, M. C. P. (2011). Significados asociados al futuro laboral: entre la formalidad y la informalidad. Pensamiento Psicológico, 9(16), 107-124. Recuperado de from http://www.scielo.org.co/scielo. php?script=sci_arttext\&pid=S1657-89612011000100008\&lng=e n\&tlng=es

Gualdi, V. (2014). Ideology as a function: Lukács and the ontology of the social being. Scienza \& Politica, 26(51), 165-185. doi: 10.6092/ issn. $1825-9618 / 4633$

Harpaz, I., \& Meshoulam, I. (2004). Differences in the meaning of work in Israel: Workers in high-tech versus traditional work industries Journal of High Technology Management Research, 15(2), 163-182. doi: 10.1016/j.hitech.2004.03.001

Harvey, D. (2010). Condição pós-moderna: uma pesquisa sobre as origens da mudana cultural. São Paulo: Edições Loyola.

Instituto Brasileiro de Geografia e Estatísticas (2003). Economia informal urbana. Distrito Federal: Autor.
Instituto Brasileiro de Geografia e Estatísticas (2018). Indicadores IBGE: pesquisa nacional por amostra de domicílios contínua - primeiro trimestre de 2018. Distrito Federal: Autor.

Johnson, J. M. (2002). In-depth interviewing. In J. F. Gubrium \& J. A. Holstein (Orgs.), Handbook of interview research: context \& method (pp. 103-119). California: Sage Publications.

Löwy, M. (2010) Ideologias e ciência social: elementos para uma análise marxista. Rio de Janeiro: Cortez.

Lu, Q., Huang, X., \& Bond, M. H. (2016). Culture and the working life: Predicting the relative centrality of work across life domains for employed persons. Journal of Cross-Cultural Psychology, 47(2), 277-293. doi: 10.1177\%2F0022022115615235

Ludermir, A., \& Lewis, G. (2003) Informal work and common mental disorders. Social Psychiatry and Psychiatric Epidemiology, 38(9), 485-489. doi: 10.1007/s00127-003-0658-8

Lukács, G. (2013) Para uma ontologia do ser social II. São Paulo: Boitempo Editorial. (Obra original publicada em 1968)

Machado, R.P., \& Rocha, A. L. C. (2003) A rua como estilo de vida: práticas cotidianas na ocupação do centro de Porto Alegre por camelôs. Iluminuras, 4(7), 1-34. doi: 10.22456/1984-1191.9156

Malaguti, M. L. (2001). Crítica à razão informal: a imaterialidade do salariado. São Paulo: Boitempo Editorial.

Mattos, M. B. (2009). Trajetórias entre fronteiras: o fim da escravidão e o fazer-se da classe trabalhadora no Rio de Janeiro. Revista Mundo do Trabalho, 1, 51-64.

Mészáros, I. (2005). A educação para além do capital. São Paulo: Boitempo.

Morin, E. (1997). Le sens du travail pour des gestionnaires francophones. Revue Psychologie du Travail e des Organizations, 3(2/3), 26-45.

Morin, E. (2002). Os sentidos do trabalho. In T. Wood (Org.), Gestão empresarial: o fator humano (pp. 13-34). São Paulo, SP: Atlas.

Morse, H., \& Weiss, R. (1955). The function and meaning of work and the job.American Sociological Review, 20(2), 191-198. doi: $10.2307 / 2088325$

Meaning of Work International Research Team. (1987). The meaning of work. Londres: Academic Press.

Organização Internacional do Trabalho (2002). Resolution concerning decent work and the informal economy. Suiça: ILO.

Peixoto, T. P., \& Borges, L. O. (2015). The metals sector: Labor union relations, motivation, and meanings of work. Revista Colombiana de Psicología, 24(1), 165-181. doi: 10.15446/rcp.v24n1.39907

Person, K., Maya, M.S., \& Mayer, C.H. (2016). The meaning of work for South African women: A phenomenological study. Journal of Psychology in Africa, 26(2), 134-140. doi: 10.1080/14330237.2016.1163897

Rebouças, F. R. (2011). Periferia e economia informal urbana: camelôs do bairro de São Caetano, subúrbio rodoviário da metrópole baiana. Revista Bibliográfica de Geografía y Ciencias sociales 15(938), 742-798.

Rosso, B. D., Dekas, K. H., \& Wrzesniewski, A. (2010). On the meaning of work: A theoretical integration and review. Research on Organizacional Behavior, 30(2010), 91-127. doi: 10.1016/j.riob.2010.09.001

Schweitzer, L., Gonçalves, J., Tolfo, S. R., \& Silva, N. (2016). Bases epistemológicas sobre sentido(s) e significado(s) do trabalho em estudos nacionais. Revista Psicologia: Organizações e Trabalho, 16(1), 103-116. Recuperado de http://pepsic.bvsalud.org/scielo. php?script=sci_arttext\&pid=S1984-66572016000100009\&lng=pt \&tlng $=p t$ 
Ideologia, significado e trabalho informal

Seale, C. (1999). Quality in qualitative research. Qualitative Inquiry, 5(4), 465-478. doi: 10.1177\%2F107780049900500402

Siegmann, K. A., \& Schiphorst, F. (2016). Understanding the globalizing precariat: From informal sector to precarious work. Progress in Development Studies, 16(2), 111-123. doi: $10.1177 \% 2 \mathrm{~F} 1464993415623118$
Tavares, M. A. (2010). O trabalho informal e suas funções sociais. Praia Vermelha, 20, 21-36. Recuperado de https://docs.google.com/ file/d/OBO--tS_Kbeq-ZHItWUJ3WIhXNkU/edit

Vygotsky, L. S. (2009). A construção do pensamento e da linguagem São Paulo: Martins Fontes. (Obra original publicada em 1934).

1. Agradecemos à Comissão de Aperfeiçoamento de Pessoal do Nível Superior pela concessão de bolsa de pós-graduação para o primeiro autor, viabilizando a realização dessa pesquisa.

Fellipe Coelho-Lima Doutor em Psicologia pela Universidade Federal do Rio Grande do Norte (UFRN), é Professor Adjunto do Departamento de Psicologia da Universidade Federal do Rio Grande do Norte (UFRN). Endereço para correspondência: Departamento de Psicologia - CCHLA - UFRN, Lagoa Nova, Campus Universitário. Telefone: (84) 3342-2236. E-mail: fellipecoelholima@gmail.com

Pedro F. Bendassolli, Doutor em Psicologia Social pela Universidade de São Paulo (USP), Pós-doutorado na Université Paris-Dauphine (Paris IX), na Universidade de Brasília (UnB) e na Aalborg University (AAU), é Professor Associado do Departamento de Psicologia da Universidade Federal do Rio Grande do Norte (UFRN). E-mail: pbendassolli@gmail.com

Recebido em 28.Jul.17 Revisado em 05.Dez.18 Aceito em 22.Mar.19 